\title{
Research Article \\ Effect of Gas Permeability and Solubility on Foam
}

\author{
Rouhollah Farajzadeh, ${ }^{1,2}$ Sebastian Vincent-Bonnieu, ${ }^{2}$ and Nacera Bourada Bourada ${ }^{1,3}$ \\ ${ }^{1}$ Department of Geoscience and Engineering, Delft University of Technology, Stevinweg 1, \\ 2628 CN Delft, The Netherlands \\ ${ }^{2}$ Shell Global Solutions International, Kessler Park 1, 2288 GS Rijswijk, The Netherlands \\ ${ }^{3}$ Schlumberger Well Services Cementing Norway, Norway \\ Correspondence should be addressed to Rouhollah Farajzadeh; r.farajzadeh@tudelft.nl
}

Received 26 August 2014; Revised 10 November 2014; Accepted 10 November 2014; Published 30 November 2014

Academic Editor: Eri Yoshida

Copyright (C) 2014 Rouhollah Farajzadeh et al. This is an open access article distributed under the Creative Commons Attribution License, which permits unrestricted use, distribution, and reproduction in any medium, provided the original work is properly cited.

\begin{abstract}
We perform a study on the influence of gas permeability and solubility on the drainage and stability of foam stabilized with an anionic surfactant. Our study compares the foam stability for four pure gases and two gas mixtures while previous works only compared two pure gases. Drainage and foam-volume-decay rates are calculated from the experimental data and analysed. We find good agreement with existing theory as the foam stability is strongly influenced by the properties of the gas phase, in particular its solubility in the aqueous phase (measured by Henry's solubility constant, $k_{H}$ ) and permeability (measured by foamfilm permeability coefficient, $K$ ). The foam volume decreases considerably with increasing $K$. Moreover, we observe that foams are more stable when a less soluble gas is added to a more soluble gas. Our analysis confirms theories linking drainage, stability, and coarsening rate. Finally, we introduce a new formulation for the foaming index that considers gas solubility and permeability.
\end{abstract}

\section{Introduction}

Aqueous foams are dispersions of a gas in a surfactant solution (containing water, surfactant, and possibly electrolyte or particles) [1-3]. Similar to the liquid phase, the gas phase might consist of more than a single component. For instance, when foam is applied in petroleum industry for improving the oil production, the gases are often mixtures of a number of gases. Another example includes direct utilization of the flue gas (mixture of $\mathrm{N}_{2}, \mathrm{CO}_{2}$, and $\mathrm{NO}_{x}$ 's) in several applications, which aims at reducing costs of separation of $\mathrm{CO}_{2}$ from flue gas.

Foam can be characterized by physicochemical properties of its constitutive components, such as bubble shape and size, liquid fraction, and film thickness $[1,2,4]$. The properties of both phases (and the components in the phases) control the dynamics of foam behaviour and eventually affect foam longevity. While many studies have shown the impact of the components of the aqueous phase on foam stability $[1,4-9]$, the effect of type and composition of the gaseous phase has received less attention.
Foam stability is controlled by three main factors: drainage, coarsening, and bubble coalescence. Coarsening refers to the growth of the average bubble size. Two processes are responsible for the changes in degree of dispersion of gas bubbles in foam: (i) the diffusion of gas through the lamellae and (ii) collapse of liquid lamellae and subsequent coalescence of contiguous gas bubbles. Pressure difference between bubbles of unequal size induces gas transfer from small to larger bubbles [10-13].

The ability of gas to permeate through a foam film is measured by a constant referred to as the "permeability coefficient, $K$," which depends on the properties of the foam components, for example, type of surfactant, concentration of surfactant and electrolyte in the foaming solution, temperature, and solubility of the gaseous phase in the aqueous phase [11-23]. It appears from experimental data that $K$ is directly proportional to the product of the molecular diffusion coefficient, $D$, of the gas in the aqueous phase and Henry's solubility constant $\left(k_{H}\right)$, that is, $K \propto D k_{H}$. Indeed, on a log-log plot $K$ varies linearly with $D k_{H}$ [23]. In some literature the coarsening rate of foam has been quantified 
TABLE 1: Properties of the gases used in the experiments. $K$ is the single foam film permeability to gas, $k_{H}$ is Henry's solubility constant, $D$ is the molecular diffusion coefficient, and $t_{c}$ is critical time of coarsening.

\begin{tabular}{lccccc}
\hline Gas type & $\begin{array}{c}K^{1} \\
(\mathrm{~m} / \mathrm{s})\end{array}$ & $\begin{array}{c}k_{H}{ }^{2} \\
(-)\end{array}$ & $\begin{array}{c}\mu^{3} \\
\left(10^{-3} \mathrm{cP}\right)\end{array}$ & $\begin{array}{c}D^{3} \\
\left(10^{5} \mathrm{~cm}^{2} / \mathrm{s}\right)\end{array}$ & $\begin{array}{c}D \times k_{H} \\
\left(10^{5} \mathrm{~cm}^{2} / \mathrm{s}\right)\end{array}$ \\
\hline $\mathrm{CO}_{2}$ & 7.85 & 0.831 & 14.80 & 1.90 & 5 \\
$t_{c}^{7}(\mathrm{~s})$
\end{tabular}

${ }^{1}$ Data taken from Princen et al., 1976 [12], and Princen and Mason, 1965 [13].

${ }^{2}$ Data taken from Sander, 1999 [46].

${ }^{3}$ Data taken from CRC handbook of chemistry and physics, 1980 [47].

${ }^{4}$ Calculated using (1).

${ }^{5}$ Perry's chemical engineering handbook, chapter 2 [48].

${ }^{6}$ Calculated by (7) of Norman et al., 1954 [49].

${ }^{7}$ Calculated from (3) of Hilgenfeldt et al., 2001 [32].

using an "effective" diffusion coefficient, $D_{\text {eff }}$, which depends on the ideal gas molar volume, Henry's law constant, and the gas permeability through the film [24].

For a mixture of gases, the behavior of each component gas needs to be accounted for. Princen et al. $[12,13]$ showed that the permeability coefficient of a film to a mixture of gases can be calculated using the following equation:

$$
K_{G}=\left(\sum_{i=1}^{n} \frac{x_{i}}{K_{i}}\right)^{-1},
$$

where $n$ is the number of components and $x_{i}$ and $K_{i}$ are the mole fraction and permeability of the film to component $i$, respectively. Princen and Mason [13] argued that the gases diffuse out of the bubble at nearly the same ratio as their respective mole fractions inside the bubble, so that the mole fractions subsequently change very slowly. An important implication of (1) is that the diffusion of a fast-permeating gas can be slowed down by admixing it with a slow-permeating gas, which leads to more stability of the foam [25].

The transfer of gas through lamellae is governed by the thermodynamics of the single foam films; that is, the interactions of the two adsorbed monolayers result in slower coarsening rates than the Fickian diffusion [26-29]. Films also rupture when the liquid fraction is too small for transient films to be formed [27, 29-31].

The coarsening depends on liquid fraction, bubble size, the chemistry of the liquid, and the gas type [14-23]. Note that drainage, coarsening, and coalescence are coupled phenomena. During foam coarsening, gravity-driven drainage redistributes the liquid in the foam. After a certain time, drainage rate decreases and coarsening becomes significant. This time is referred to as the critical time of coarsening, $t_{c}$ [32]. The $t_{c}$ of the gases used in this work is listed in Table 1 . Saint-Jalmes et al. saturated the $\mathrm{N}_{2}$ gas with $\mathrm{SF}_{6}$ or $\mathrm{C}_{2} \mathrm{~F}_{6}$ to suppress the coarsening and study the modification of the drainage [24, 33-36]. It has been observed that the gas with higher solubility leads to a foam with higher drainage rate $[15,24]$. Similar behavior has been observed in emulsions, where Ostwald ripening is limited by addition of an insoluble oil [37]. Gas solubility also affects foam stability in porous media [23, 25, 38-43], although the underlying mechanisms are not as straightforward as the foam in bulk [39].

Previous works have demonstrated that strong coarsening accelerates the drainage and shortens the foam lifetime $[24,32,44,45]$. These studies have compared gases with large difference in their solubilities such as $\mathrm{CO}_{2}$ and $\mathrm{C}_{2} \mathrm{~F}_{6}$. Furthermore, the effects of gas solubility and permeability on the foamability have not yet been quantified.

Our objective is therefore to experimentally investigate the effect of gas type and composition on foam generation, drainage, coarsening, and coalescence. Foam was created by gas sparging and foam volume and liquid fraction was continuously monitored. Experiments were conducted with gases of different solubility and permeability in water and with mixtures of gases. The foams were characterized by their foaming time, volume, drainage rate, and the permeability of their single films to the respective gas. The structure of the paper is as follows. First we describe the experimental setup and the material used in the experiments. Afterwards, we examine foaming and the stability of foams and relate foam physics to the properties of the gases. Finally, we end the paper with concluding remarks.

\section{Experiments}

2.1. Material. The surfactant used was $\left(\mathrm{C}_{14}-\mathrm{C}_{16}\right)$-alpha-olefin sulfonate, AOS (Stepan Company, USA). This surfactant is anionic with industrial purity and was used as received without any further purification. The molecular weight of the surfactant is $M_{w} \approx 315$. Properties of the solution and single foam films stabilized by this surfactant can be found in [50]. Sodium chloride ( $\mathrm{NaCl})$ was used as electrolyte. The surfactant solution used in all experiments contained $2 \mathrm{wt} \%$ $\mathrm{AOS}$ and $3 \mathrm{wt} \% \mathrm{NaCl}$.

Surface tension was measured only in air and was not measured in the presence of the different gases used in foam generation. 
All the gases $\left(\mathrm{CO}_{2}, \mathrm{CH}_{4}, \mathrm{~N}_{2}\right.$, and $\left.\mathrm{He}\right)$ were with purities of above $99 \%$. For the gas mixtures, the first was a synthetic flue gas made from $\mathrm{N}_{2}$ and $\mathrm{CO}_{2}$ (in an $80 \% / 20 \%$ molar fraction mix), and the second was a $50 \% / 50 \%$ mixture of $\mathrm{CO}_{2}$ and $\mathrm{CH}_{4}$. The main properties of the gases, and gas mixtures, are summarized in Table 1 . The film permeability coefficient, $K$, of the gas mixtures was calculated using (1). Henry's solubility constant, $k_{H}$, and the molecular diffusion coefficient, $D$, of the gas mixtures were assumed to be a linear function of the molar fraction of the pure gases. All the experiments were performed at atmospheric pressure and room temperature $\left(\sim 20^{\circ} \mathrm{C}\right)$.

2.2. Foaming Setup. This study was carried out using the Foamscan apparatus (manufactured by Teclis), an experimental setup commonly used to study foam drainage and stability $[5,51,52]$. The foam was generated in a glass column (with an inner diameter of $3 \mathrm{~cm}$ ) by sparging gas though a glass frit (with a thickness of $3 \mathrm{~mm}$ and pore sizes in the range $40-100 \mu \mathrm{m}$ ) at the bottom of $50 \mathrm{~mL}$ of surfactant solution. During foam generation the gas was injected at a fixed rate of $10 \mathrm{~mL} / \mathrm{min}$, and the system was set to stop injection automatically after the foam volume in the column reached $100 \mathrm{~mL}$.

A pair of electrodes at the bottom of the column measured the volume of the free liquid. A camera measured the total height of the foam top. The foam volume was calculated by subtracting the liquid volume from the total volume. Additionally, a conductimetry technique [53] was used to measure the liquid fraction $\varepsilon$, with two pairs of electrodes positioned on opposing sides of the column to measure the liquid fractions during each experiment.

To check the repeatability of the experiments, each experiment was run twice. The difference between repetitions was of the order of a small percent.

2.3. Foaming Index. The foaming properties of gases with different solubility in water were tested using the same surfactant solution and foaming procedure for each gas. The foamability (ability to create the foam) was quantified by the foaming index (FI), defined as the ratio of the foaming rate, $r_{f}(t)$ (the volume of foam, $V_{f}(t)$, created per unit time, i.e., $\left.r_{f}(t) \equiv d V_{f}(t) / d t\right)$, and the rate at which gas was injected $r_{g}(t):$

$$
\mathrm{FI} \equiv \frac{r_{f}(t)}{r_{g}(t)} \equiv \frac{V_{f}(t)}{V_{g}(t)} .
$$

The FI is similar to the coefficient $\Omega$ introduced by Bikerman in 1938 [54] to describe foam behavior during steady-state experiments. In contrast the FI can be used to describe transient, or foaming phase, experiments. Hrma [55] and Capek [37] have disputed the consistency of FI due to its dependency on the gas rate. However in this study all the experiments were conducted with the same gas injection rate and therefore FI is a good measure of foamability of the gases. The FI can be larger than unity when small amounts of water are entrained within the bubbles. In this case foaming is assumed to be very efficient. On the contrary, FI below

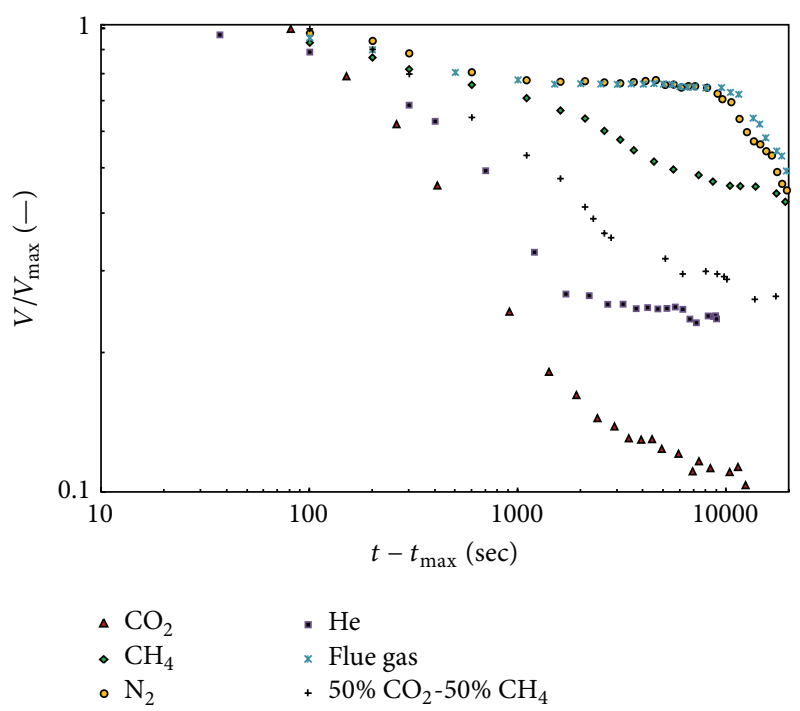

FIgURE 1: Evolution of foam with time for different gases. To eliminate the generation stage, foam volume has been plotted versus $\left(t-t_{\max }\right)$, where $t_{\max }$ is the time at which foam volume reaches its maximum value in the experiment.

unity indicates collapse of foam and implies lower foaming efficiency. In this case a large volume of gas is required to create a certain foam volume.

\section{Results and Discussion}

3.1. Foam Generation and Destruction. An important feature of foam is its irreversible evolution with time to achieve minimum free energy through minimization of its surface area [4]. For all our experiments, the maximum volume of the foam was set to be $100 \mathrm{~mL}$. We assign $t_{\max }$ to be the time at which the foam volume reached this maximum value for the constant gas injection rate used. Once the foam volume reached its maximum value the gas injection stopped.

The general characteristics of the experiments for all gases are largely similar. Foam volume increases with injection of gas, more strictly after the foaming solution is saturated with the injected gas. Once the foam volume reaches its maximum value, the gas injection stops and therefore foam is no longer generated. The evolution of foam volume as a function of time is shown in Figure 1 for the gases examined.

Foam evolution proceeds in three phases for all gases. (i) Initially, the foam does not drain; the liquid is held in the foam due to capillary suction [32]. The liquid fraction $\varepsilon$ is around $20 \%$. During this period the bubbles rearrange to find a stable structure. The effect of the coarsening is relatively small as the critical coarsening time $t_{c}$ is bigger than the age of the foam (Table 1). (ii) In the second phase, the foam starts to drain due to gravity but the foam volume is constant. The drainage enhances coarsening and the consequent rearrangement of the bubbles [32]. (iii) The third phase is dominated by coarsening and coalescence. The foam volume decreases due to coalescence. The drainage rate declines with time as foam becomes drier. During this stage, black films (common or 


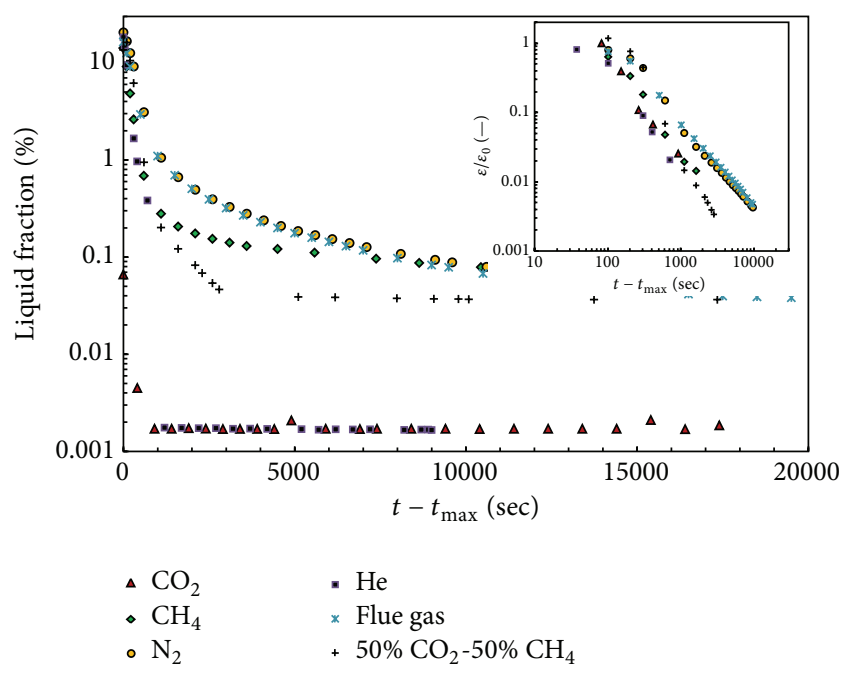

FIGURE 2: Liquid fraction of the foam as a function of time for different gases.

Newtonian) are likely to be formed. The transition from the phases (ii) to (iii) is distinct only for $\mathrm{N}_{2}$ and flue gas. The transition time between the two stages decreases as the solubility of gas increases. Indeed, with $\mathrm{He}$ and $\mathrm{CO}_{2}$ stages (ii) and (iii) cannot be distinguished. Volume of the foam is inversely related to solubility of the gas in the aqueous solution at any time of the experiment; that is, the lower the gas solubility the larger the volume of the foam. Moreover, addition of insoluble gas to a soluble gas results in more stable foam.

3.2. Effect of Gas Solubility on Drainage. Figure 2 shows the variations of liquid fraction with time in the foams created with different gases. Foams made with helium and carbon dioxide become very dry within few minutes at the stop of foam generation. This leads to very unstable foam. The helium foam height stabilizes within few minutes, not long after the foam becomes very dry at $1000 \mathrm{sec}$. The behavior of $\mathrm{He}$ can be due to the high diffusion coefficient of $\mathrm{He}$, which overcompensates its low solubility in water. Furthermore, we observe from Figure 2 that at the end of the experiment the fraction of liquid in all other gases reaches a similar value, within measurement accuracy of the apparatus.

As an inset of Figure 1, the liquid fraction $\varepsilon / \varepsilon_{0}$ (normalized by the amount of liquid $\varepsilon_{0}$ at $t_{\max }$ ) is presented for all gases on a $\log$ - $\log$ scale. $\varepsilon_{0}$ is the initial liquid fraction at $t-t_{\max }=0$. The slopes of $\varepsilon / \varepsilon_{0}$-time curves are indicators of the rate of liquid drainage from the foam films for each gas and are shown in Figure 3(a). We observe that the drainage rate scales with Henry's solubility constant; that is, the higher the solubility of the gas the higher the rate of drainage. The drainage rate of the foams with mixture of gasses is between the drainage rate of the foams with individual gases.

3.3. Effect of Gas Permeability on Coalescence. The slopes of linear part of foam volume $V / V_{\max }$-time curve (Figure 1) are indicators of the foam decay rate and are shown in
Figure 3(b). As explained in the introduction, the coalescence is driven by the coarsening [27, 29], which depends on the permeability coefficient of the single foam films. The foam decay rate scales with the gas permeability $K$ of the single foam films. Remarkably, the gas mixture (flue gas and $\mathrm{CH}_{4} / \mathrm{CO}_{2}$ ) behaves similar to the less permeable gas, respectively, $\mathrm{N}_{2}$ and $\mathrm{CH}_{4}$. The only exception in the trend is He. Most of the gases have a critical coarsening time $t_{c}$ in the range of the foaming time except for He for which $t_{c}$ is 10 times bigger (see Table 1). $\mathrm{CO}_{2}$ foams are expected to coarsen during the foaming as $t_{c}$ is 5 seconds, which is shorter than the foaming time.

The liquid fraction and foam stability seem to be, respectively, influenced by the permeability and solubility of the gas. Thus, the foaming should be a combination of permeability and solubility. This model will be studied in the next section.

3.4. Effect of Gas Solubility on the Foaming. As the foam is generated, gas is solubilized (quantified by Henry's solubility constant $\left.k_{H}\right)$. Coarsening can also occur if $t_{c}$ is shorter than the foaming time. Figure 4 plots the foaming index (FI) of different gasses as a function of Henry's solubility constant. The FI decreases with increasing gas solubility, implying that more gas is required to produce a certain volume of foam as the gas solubility in the aqueous solution increases. Because the surfactant solutions were not saturated with the gas injected prior to the test, the gas dissolves in the solution during the foaming, which decreases the foaming efficiency and the foaming index, accordingly.

To quantify the effect of gas dissolution, the FI is modeled by considering the volume of gas dissolved. Assuming that during the foaming stage the gas fully saturates the surfactant solution (i.e., the gas is dissolved up to the limit given by Henry's law in $50 \mathrm{~mL}$ of water), the foaming index can be modeled with a simple equation. Assuming a constant $r_{f}$ during foaming in (2), the $\mathrm{FI}_{\text {model }}$ can be approximated by

$$
\mathrm{FI}_{\text {model }}=\frac{V_{f}}{V_{g}+V_{\text {dis }}},
$$

where $V_{g}$ is the volume of gas in the foam, $V_{f}$ is the final volume of foam, and $V_{\text {dis }}$ is the volume of gas dissolved in the $50 \mathrm{~mL}$ water calculated with Henry's constant. Defining $\mathrm{FI}_{0}=V_{f} / V_{g}$, corresponding to the FI without gas dissolution (3) becomes

$$
\mathrm{FI}_{\text {model }}=\frac{1}{1 / \mathrm{FI}_{0}+V_{\mathrm{dis}} / V_{f}}
$$

This equation takes into account the direct effect of gas solubility on the foaming index. Comparing the results obtained from (4) with the foaming index calculated from experimental data (Figure 4) reveals that as the gas solubility increases the mismatch between the model and the data becomes more significant. This indicates that for gas with a high dissolution in the aqueous phase the coalescence rate becomes considerable even in the generation stage.

In order to represent the coarsening, we introduce a volume of the coalesced foam during the generation stage, 


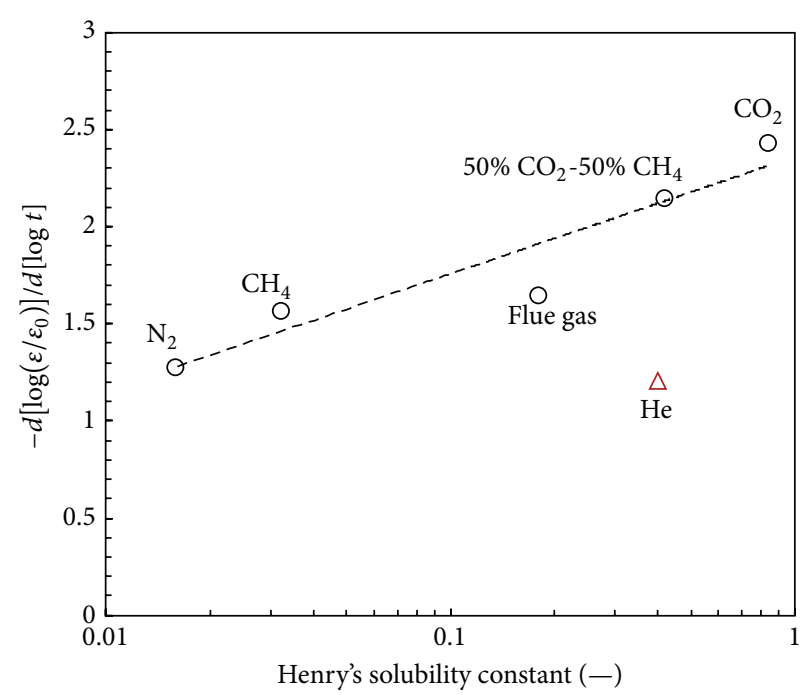

(a)

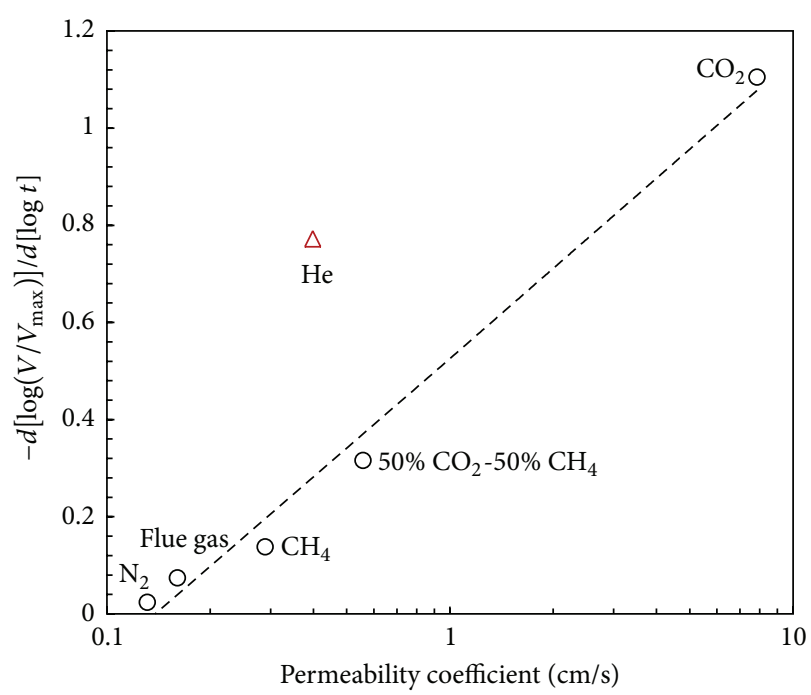

(b)

FIGURE 3: Foam drainage versus solubility of the gas and foam decay rate versus gas permeability of single foam films.

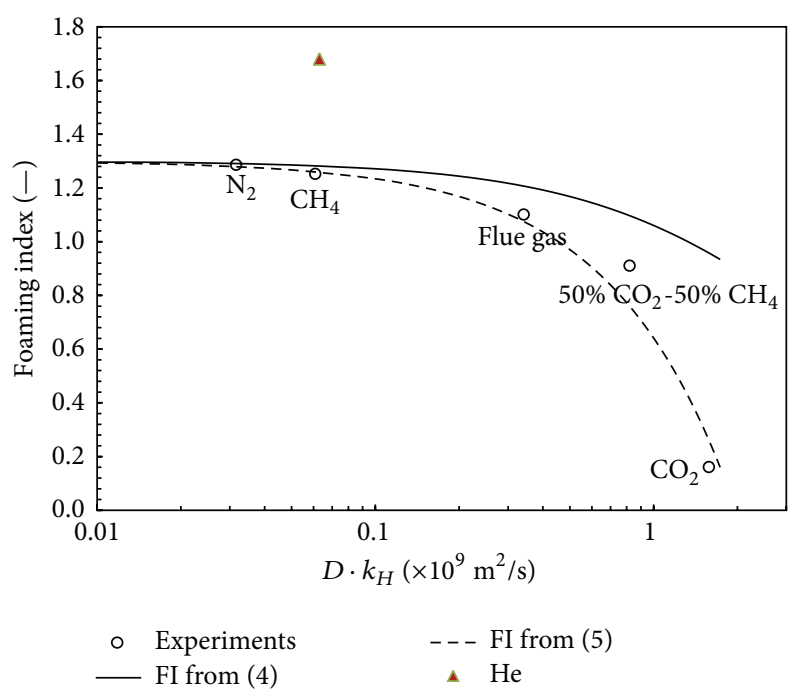

FIGURE 4: Foaming index as a function of gas solubility in the aqueous phase.

$V_{\text {coal }}$ represented by the ratio $V_{\text {coal }} / V_{f}$. We assume that $V_{\text {coal }}$ is proportional to the film permeability; that is, $V_{\text {coal }} / V_{f}=$ $\alpha K$. Consequently (4) can be modified to include the foam coalescence in the foaming index:

$$
\mathrm{FI}_{\text {model }}=\frac{V_{f}-V_{\text {coal }}}{V_{g}+V_{\text {dis }}}=\frac{1-\alpha K}{1 / \mathrm{FI}_{0}+V_{\text {dis }} / V_{f}} .
$$

The dashed line in Figure 4 is calculated using (5). The fit is obtained by changing the value of constant $\alpha$ to 0.5 .

\section{Conclusions}

A study was conducted to understand the effect of the composition of the gaseous phase on the macroscopic properties of foam. The properties of the foam can be characterized using Henry's solubility constant $k_{H}$ and the gas permeability coefficient of single foam films, $K$. The drainage rate increases with increasing gas solubility, while foam-decay rate increases considerably with increasing $K$. While both drainage and decay rates are influenced when a low-solubility gas is added to a high-solubility gas, the contribution to foam stability is mainly due to reduction in the coarsening rate. With increasing gas solubility the foam coarsening coalescence significantly increases even in the generation stage of foam. This results in poor foaming behavior as the gas solubility in the aqueous phase increases. The foaming index should consider the gas solubility and permeability. Results of helium foam suggest some additional factors must be taken into account in the model.

\section{Conflict of Interests}

The authors declare that there is no conflict of interests regarding the publication of this paper.

\section{Acknowledgments}

The authors thank the technical staff in the Dietz laboratory of the Department of Geoscience and Engineering at Delft University of Technology. They are grateful to Professor William R. Rossen for his invaluable comments on the draft of this paper. They thank Dr. Sian Jones for her detailed comments and suggestions. The authors also thank Shell Global Solutions International for financial support of the work and for granting permission to publish this study.

\section{References}

[1] D. Exerowa and P. Kruglyakov, Foam and Foam Films, Elsevier Science, New York, NY, USA, 1998. 
[2] D. Weaire and S. Hutzler, The Physics of Foams, Oxford University Press, New York, NY, USA, 1999.

[3] W. R. Rossen, "Foams in Enhanced Oil Recovery," in Foams, Theory: Measurements and Applications, R. K. Prud'homme and S. A. Khan, Eds., p. 413, Marcel Dekker, New York, NY, USA, 1996.

[4] A. de Vries, Foam Stability: A Fundamental Investigation of the Factors Controlling the Stability of Foams, Communication no. 326, Rubber-Stichting, Delft, The Netherlands, 1957.

[5] S. Jun, D. D. Pelot, and A. L. Yarin, "Foam consolidation and drainage," Langmuir, vol. 28, no. 12, pp. 5323-5330, 2012.

[6] J. Heuser, J. Moller, W. Spendel, and G. Pacey, "Aqueous foam drainage characterized by terahertz spectroscopy," Langmuir, vol. 24, no. 20, pp. 11414-11421, 2008.

[7] A. Bhakta and E. Ruckenstein, "Drainage of a standing foam," Langmuir, vol. 11, no. 5, pp. 1486-1492, 1995.

[8] S. A. Koehler, S. Hilgenfeldt, and H. A. Stone, "Generalized view of foam drainage: experiment and theory," Langmuir, vol. 16, no. 15, pp. 6327-6341, 2000.

[9] J. L. Joye, G. J. Hirasaki, and C. A. Miller, "Asymmetric drainage in foam films," Langmuir, vol. 10, no. 9, pp. 3174-3179, 1994.

[10] J. A. Attia, S. Kholi, and L. Pilon, "Scaling laws in steadystate aqueous foams including Ostwald ripening," Colloids and Surfaces A: Physicochemical and Engineering Aspects, vol. 436, pp. 1000-1006, 2013.

[11] R. Farajzadeh, R. Krastev, and P. L. J. Zitha, "Foam film permeability: theory and experiment," Advances in Colloid and Interface Science, vol. 137, no. 1, pp. 27-44, 2008.

[12] H. M. Princen, J. T. G. Overbeek, and S. G. Mason, "The permeability of soap films to gases: II. A simple mechanism of monolayer permeability," Journal of Colloid And Interface Science, vol. 24, no. 1, pp. 125-130, 1967.

[13] H. M. Princen and S. G. Mason, "The permeability of soap films to gases," Journal of Colloid Science, vol. 20, no. 4, pp. 353-375, 1965.

[14] K. Feitosa, O. L. Halt, R. D. Kamien, and D. J. Durian, "Bubble kinetics in a steady-state column of aqueous foam," Europhysics Letters, vol. 76, no. 4, pp. 683-689, 2006.

[15] S. J. Neethling, H. T. Lee, and P. Grassia, "The growth, drainage and breakdown of foams," Colloids and Surfaces A: Physicochemical and Engineering Aspects, vol. 263, no. 1-3, pp. 184-196, 2005.

[16] M. Nedyalkov, R. Krustev, A. Stankova, and D. Platikanov, "Mechanism of permeation of gas through Newton black films at different temperatures," Langmuir, vol. 8, no. 12, pp. 31423144, 1992.

[17] R. Krustev, D. Platikanov, and M. Nedyalkov, "Permeability of common black foam films to gas. Part 1," Colloids and Surfaces A, vol. 79, no. 1, pp. 129-136, 1993.

[18] R. Krustev, D. Platikanov, A. Stankova, and M. Nedyalkov, "Permeation of gas through newton black films at different chain length of thesurfactant," Journal of Dispersion Science and Technology, vol. 18, pp. 789-800, 1997.

[19] R. M. Muruganathan, H.-J. Müller, H. Mühwald, and R. Krastev, "Effect of headgroup size on permeability of newton black films," Langmuir, vol. 21, no. 26, pp. 12222-12228, 2005.

[20] R. M. Muruganathan, R. Krustev, N. Ikeda, and H. J. Müller, "Temperature dependence of the gas permeability of foam films stabilized by dodecyl maltoside," Langmuir, vol. 19, no. 7, pp. 3062-3065, 2003.

[21] P. N. Quoc, P. L. J. Zitha, and P. K. Currie, "Effect of foam films on gas diffusion," Journal of Colloid and Interface Science, vol. 248, no. 2, pp. 467-476, 2002.
[22] R. Krustev and H. J. Müller, "Effect of film free energy on the gas permeability of foam films," Langmuir, vol. 15, no. 6, pp. 21342141, 1999.

[23] R. Farajzadeh, R. M. Muruganathan, W. R. Rossen, and R. Krastev, "Effect of gas type on foam film permeability and its implications for foam flow in porous media," Advances in Colloid and Interface Science, vol. 168, no. 1-2, pp. 71-78, 2011.

[24] A. Saint-Jalmes, "Physical chemistry in foam drainage and coarsening," Soft Matter, vol. 2, no. 10, pp. 836-849, 2006.

[25] A. H. Falls, J. B. Lawson, and G. J. Hirasaki, “The role of noncondensable gas in steam foams," Journal of Petroleum Technology, vol. 40, no. 1, pp. 95-104, 1988.

[26] R. Farajzadeh, R. Krastev, and P. L. J. Zitha, "Gas permeability of foam films stabilized by an $\alpha$-olefin sulfonate surfactant," Langmuir, vol. 25, no. 5, pp. 2881-2886, 2009.

[27] A. L. Biance, A. Delbos, and O. Pitois, "How topological rearrangements and liquid fraction control liquid foam stability," Physical Review Letters, vol. 106, no. 6, Article ID 068301, 4 pages, 2011.

[28] S. D. Stoyanov and N. D. Denkov, "Role of surface diffusion for the drainage and hydrodynamic stability of thin liquid films," Langmuir, vol. 17, no. 4, pp. 1150-1156, 2001.

[29] V. Carrier, S. Destouesse, and A. Colin, "Foam drainage: a film contribution?" Physical Review E: Statistical, Nonlinear, and Soft Matter Physics, vol. 65, no. 6, Article ID 061404, 2002.

[30] E. J. W. Verwey and J. T. G. Overbeek, Theory of the Stability of Lyophobic Colloids, Elsevier, Amsterdam, The Netherlands, 1948.

[31] V. Bergeron, "Disjoining pressures and film stability of alkyltrimethylammonium bromide foam films," Langmuir, vol. 13, no. 13, pp. 3474-3482, 1997.

[32] S. Hilgenfeldt, S. A. Koehler, and H. A. Stone, "Dynamics of coarsening foams: accelerated and self-limiting drainage," Physical Review Letters, vol. 86, no. 20, pp. 4704-4707, 2001.

[33] A. Saint-Jalmes, M. U. Vera, and D. J. Durian, "Uniform foam production by turbulent mixing: new results on free drainage vs. liquid content," European Physical Journal B, vol. 12, no. 1, pp. 67-73, 1999.

[34] A. Saint-Jalmes and D. Langevin, "Time evolution of aqueous foams: drainage and coarsening," Journal of Physics: Condensed Matter, vol. 14, p. 9397, 2002.

[35] A. Saint-Jalmes, Y. Zhang, and D. Langevin, "Quantitative description of foam drainage: transitions with surface mobility," The European Physical Journal E, vol. 15, pp. 53-60, 2004.

[36] G. Maurdev, A. Saint-Jalmes, and D. Langevin, "Bubble motion measurements during foam drainage and coarsening," Journal of Colloid and Interface Science, vol. 300, no. 2, pp. 735-743, 2006.

[37] I. Capek, "Degradation of kinetically-stable o/w emulsions," Advances in Colloid and Interface Science, vol. 107, no. 2-3, pp. 125-155, 2004.

[38] R. Farajzadeh, A. Andrianov, R. Krastev, G. J. Hirasaki, and W. R. Rossen, "Foam-oil interaction in porous media: implications for foam assisted enhanced oil recovery," Advances in Colloid and Interface Science, vol. 183-184, pp. 1-13, 2012.

[39] L. E. Nonnekes, S. J. Cox, and W. R. Rossen, "Effect of gas diffusion on mobility of foam for EOR," in Proceedings of the SPE Annual Technical Conference and Exhibition, San Antonio, Tex, USA, October 2012.

[40] D. Cohen, T. W. Patzek, and C. J. Radke, "Two-dimensional network simulation of diffusion-driven coarsening of foam inside 
a porous medium," Journal of Colloid and Interface Science, vol. 179, no. 2, pp. 357-373, 1996.

[41] D. Cohen, T. W. Patzek, and C. J. Radke, "Onset of mobilization and the fraction of trapped foam in porous media," Transport in Porous Media, vol. 28, no. 3, pp. 253-284, 1997.

[42] D.-X. Du, A. N. Beni, R. Farajzadeh, and P. L. J. Zitha, "Effect of water solubility on carbon dioxide foam flow in porous media: an X-ray computed tomography study," Industrial and Engineering Chemistry Research, vol. 47, no. 16, pp. 6298-6306, 2008.

[43] R. Farajzadeh, A. Andrianov, H. Bruining, and P. L. J. Zitha, "Comparative study of $\mathrm{CO}_{2}$ and $\mathrm{N}_{2}$ foams in porous media at low and high pressure-temperatures," Industrial and Engineering Chemistry Research, vol. 48, no. 9, pp. 4542-4552, 2009.

[44] S. A. Koehler, S. Hilgenfeldt, and H. Stone, "Flow along two dimensions of liquid pulse in foams: experiment and theory," Europhysics Letters, vol. 54, no. 3, pp. 335-341, 2000.

[45] H. A. Stone, S. A. Koehler, S. Hilgenfeldt, and M. Durand, "Perspectives on foam drainage and the influence of interfacial rheology," Journal of Physics Condensed Matter, vol. 15, no. 1, pp. S283-S290, 2003.

[46] R. Sander, Compilation of Henry's Law Constants for Inorganic and Organic Species of Potential Importance in Environmental Chemistry, 1999, http://www.henrys-law.org/henry.pdf.

[47] CRC Handbook of Chemistry and Physics, 61st edition, 1980.

[48] D. W. Green and R. H. Perry, Perry's Chemical Engineers' Handbook, McGraw-Hill, 8th edition, 2008.

[49] C. Norman, R. Kobayashi, and D. Burrows, "Viscosity of hydrocarbon gases under pressure," Journal of Petroleum Technology, vol. 6, SPE-297-G, no. 10, 1954.

[50] R. Farajzadeh, R. Krastev, and P. L. J. Zitha, "Foam films stabilized with alpha olefin sulfonate (AOS)," Colloids and Surfaces A: Physicochemical and Engineering Aspects, vol. 324, no. 1-3, pp. 35-40, 2008.

[51] E. Carey and C. Stubenrauch, "Properties of aqueous foams stabilized by dodecyltrimethylammonium bromide," Journal of Colloid and Interface Science, vol. 333, no. 2, pp. 619-627, 2009.

[52] J. Boos, W. Drenckhan, and C. Stubenrauch, "Protocol for studying aqueous foams stabilized by surfactant mixtures," Journal of Surfactants and Detergents, vol. 16, no. 1, pp. 1-12, 2013.

[53] T. D. Karapantsios and M. Papara, "On the design of electrical conductance probes for foam drainage applications: assessment of ring electrodes performance and bubble size effects on measurements," Colloids and Surfaces A: Physicochemical and Engineering Aspects, vol. 323, no. 1-3, pp. 139-148, 2008.

[54] J. J. Bikerman, “The unit of foaminess," Transactions of the Faraday Society, vol. 34, pp. 634-638, 1938.

[55] P. Hrma, "Model for a steady state foam blanket," Journal of Colloid and Interface Science, vol. 134, no. 1, pp. 161-168, 1990. 

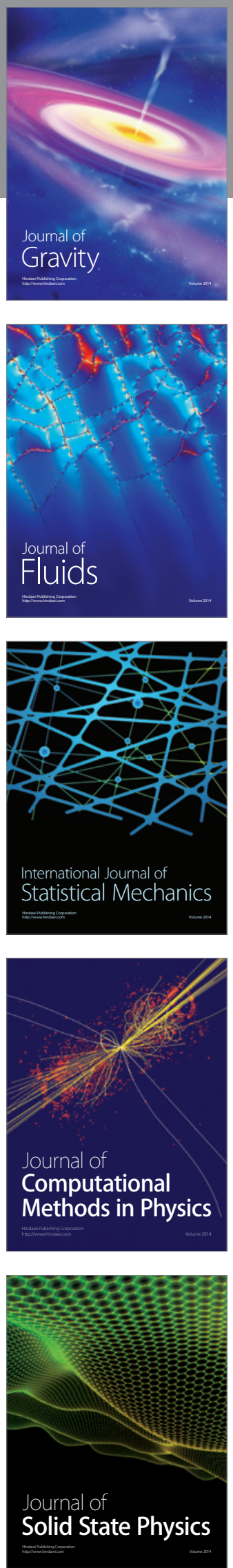

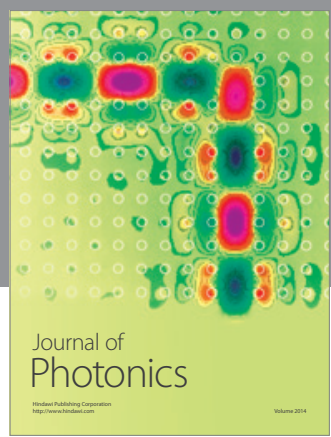

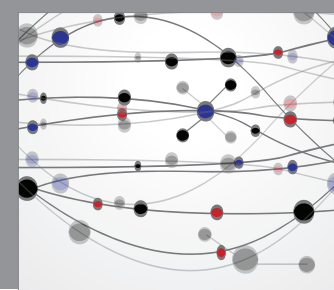

The Scientific World Journal

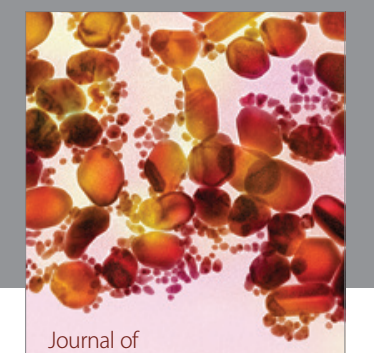

Soft Matter
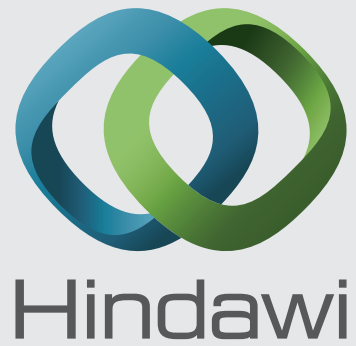

Submit your manuscripts at

http://www.hindawi.com
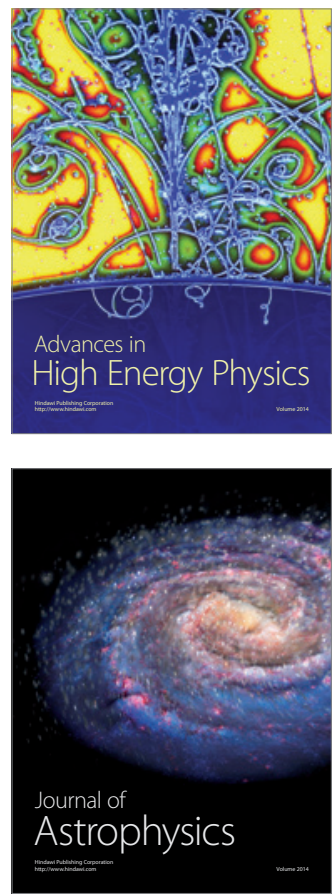
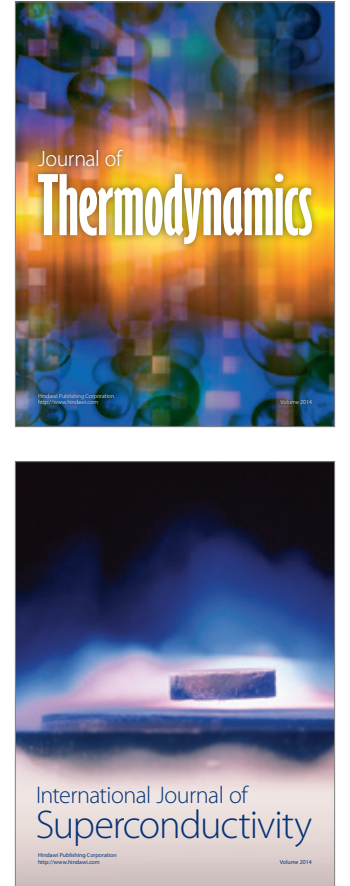
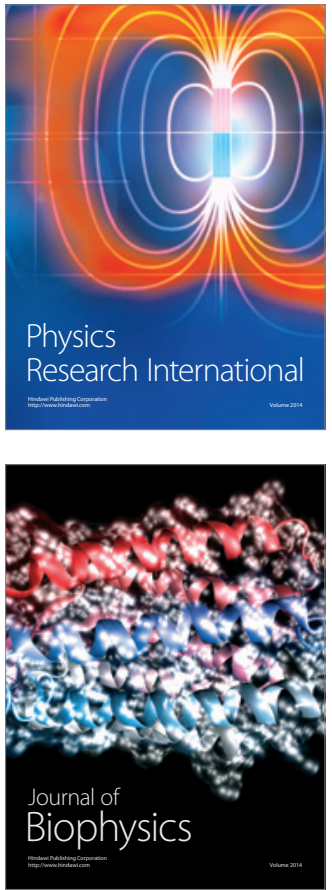
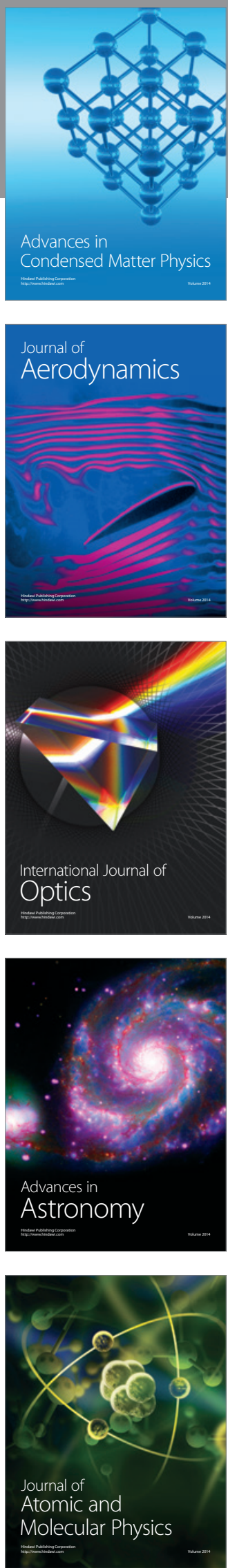